\title{
Effect of Hot Isostatic Pressing on Microstructures and Mechanical Properties of Ti6A14V Fabricated by Electron Beam Melting
}

\author{
Changyong Liu ${ }^{1}$, Zhuokeng Mai ${ }^{1}$, Deng Yan ${ }^{1}$, Mingguang Jiang ${ }^{1}$, Yuhong Dai ${ }^{2, *}$, Pei Wang ${ }^{1}$, \\ Zhangwei Chen ${ }^{1, *}$ and Changshi Lao ${ }^{1, *}$ \\ 1 Additive Manufacturing Institue, College of Mechatronics and Control Engineering, Shenzhen University, \\ Shenzhen 518060, China; liuchangyong@szu.edu.cn (C.L.); 15814671918@163.com (Z.M.); \\ yd13149904833@163.com (D.Y.); jmg_jlu@163.com (M.J.); peiwang@szu.edu.cn (P.W.) \\ 2 Shenzhen Sunshine Laser \& Electronics Co., Ltd., Shenzhen 518057, China \\ * Correspondence: yhdai@sunshine-laser.com (Y.D.); chen@szu.edu.cn (Z.C.); cslao@szu.edu.cn (C.L.)
}

Received: 11 April 2020; Accepted: 28 April 2020; Published: 30 April 2020

\begin{abstract}
This study investigated the effects of hot isostatic pressing (HIP) on the microstructures and mechanical properties of Ti6Al4V fabricated by electron beam melting (EBM). The differences of surface morphologies, internal defects, relative density, microstructures, textures, mechanical properties and tensile fracture between the as-built and HIPed samples were observed using various characterization methods including optical metallography microscopy, scanning electron microscopy (SEM), transmission electron microscopy (TEM) and electron backscattered diffraction (EBSD) and tensile tests. It was found that the main effects of HIP on microstructures include-the increase of average grain size from $7.96 \pm 1.21 \mu \mathrm{m}$ to $11.34 \pm 1.89 \mu \mathrm{m}$, the increase of $\alpha$ lamellar thickness from $0.71 \pm 0.15 \mu \mathrm{m}$ to $2.49 \pm 1.29 \mu \mathrm{m}$ and the increase of $\beta$ phase ratio from $4.7 \%$ to $10.5 \%$ in terms of area fraction on the transversal section. The combinatorial effects including densification, increase of grain size, $\alpha$ lamellar thickness, $\beta$ phase ratio, reduction of dislocation density and transformation of dislocation patterns contributed to the improvement of elongation and ductility of EBM-fabricated Ti6Al4V. Meanwhile, these effects also resulted in a slight reduction of the yield strength and UTS mainly due to the coarsening effect of HIP.
\end{abstract}

Keywords: electron beam melting; Ti6Al4V; hot isostatic pressing; microstructures

\section{Introduction}

Ti6Al4V is an important titanium alloy that has been widely used in aerospace engineering and biomedical engineering due to its high specific strength and excellent biocompatibility [1-3]. However, it has been a great challenge to process Ti6Al4V parts with complex geometries using conventional processing technologies such as machining and forging processes due to its limited machinability and deformation capacity [4]. With the development of various metal additive manufacturing technologies such as selective laser melting (SLM) and electron beam melting (EBM), complex Ti6Al4V parts can be easily fabricated in a convenient way [5].

In comparison with SLM, EBM has some unique advantages such as larger building speed, vacuum environment, higher preheating temperature, reduced residual stress and diversity of processable materials [6]. Therefore, additive manufacturing of Ti6Al4V by EBM has been extensively investigated by many research groups [5]. As for the microstructures of EBM-fabricated Ti6Al4V, it was found that transformed Widmanstätten-like $\alpha+\beta$ microstructures with acicular $\alpha$-plate was formed within the epitaxillay grown columnar $\beta$ grain [5,7-9]. Meanwhile, the microstructures of EBM-fabricated Ti6Al4V can be influenced by many factors including powder specifications [10-12], processing 
parameters [13-18], part size, shape and geometry et al [19-21]. As a result, the reported mechanical properties of EBM-fabricated Ti6Al4V fluctuated in a certain range with the ultimate tensile strength (UTS) ranging from $800 \mathrm{MPa}$ to $1400 \mathrm{MPa}$ [5]. On average, the yield strength and UTS EBM-fabricated Ti6Al4V samples are usually comparable to wrought alloys, but the elongation is usually slightly lower [7].

However, the relatively poor fatigue strength of as-built parts due to the internal and surface defects has been the main limiting factor for its applications in critical fields [22]. There are three possible ways to improve the fatigue strength [23]-(1) removing surface defects by machining or polishing, (2) relieving residual stress by heat treatment and (3) reducing internal defects by hot isostatic pressing (HIP). Among the three methods, HIP was proven to be the most effective way. HIP is a process that uses high pressure inert gas and high temperature to close internal pores and voids and finally obtain a more densified part. During this process, the microstructures and internal defects might go through a series of changes. These changes have important effects on its microstructures and mechanical properties. Lu et al., studied the microstructures and mechanical properties of EBM-fabricated long Ti6Al4V rods out of a deep powder bed $(\varphi 12 \mathrm{~mm} \times 300 \mathrm{~mm})$ and the effect of subsequent HIP [24]. They compared the differences between as-built and HIPed samples taken from three positions of the long rod including top, middle and bottom. Lu et al., further investigated the texture change induced by HIP and its effect on tensile properties for EBM-fabricated plate-shape samples $(220 \mathrm{~mm} \times 45 \mathrm{~mm} \times 5 \mathrm{~mm})$ [25]. Samuel et al., studied the effectiveness of HIP for closing porosity in EBM-fabricated Ti6Al4V with X-ray computed tomography (XCT) to track the pore closure during HIP. It was found that the internal porosity was able to shrunk to a level below the resolution limit of XCT $(\sim 5 \mu \mathrm{m})$ after HIP [26]. Wang et al., fabricated two types of Ti6Al4V samples including horizontally-built and vertically-built strips $(180 \mathrm{~mm} \times 42 \mathrm{~mm} \times 3 \mathrm{~mm})$ with EBM [27]. The mechanical properties of as-built and HIPed samples were compared. Hernández-Nava et al., demonstrated a method to combine EBM and HIP to produce Ti6Al4V with more equiaxed microstructures and isotropic properties [28]. They used EBM to generate a thin hollow preform and then filled it with sintered powder. Finally, HIP was used to densify the part to full density. Persenot et al., studied the effect of HIP and chemical etching post-treatment as well as combination of both on the mechanical properties of EBM-fabricated thin Ti6Al4V parts with complex geometries [29]. Other post-treatment procedures such as ultrasonic vibration was also explored [30]. Although there have been several studies on the effect of HIP on EBM-fabricated Ti6Al4V, there still need a study on detailed differences between as-built and HIPed samples.

In this study, cylindrical samples with the size of $\varphi 15 \mathrm{~mm} \times 86 \mathrm{~mm}$ were fabricated via EBM. HIP process was applied to densify the samples. Then the differences of surface morphologies, internal defects, relative density, microstructures, textures and mechanical properties between as-built and HIPed sampled were investigated with various characterization methods. The effect of HIP on EBM-fabricated Ti6Al4V was revealed.

\section{Materials and Methods}

\subsection{Materials and Fabrication Methods}

Ti6Al4V powder with the size of 45-105 $\mu \mathrm{m}$ was purchased from AP\&C, Saint-Eustache, QC, Canada and the nominal chemical compositions are shown in Table 1. $\varphi 15 \mathrm{~mm} \times 86 \mathrm{~mm}$ cylindrical samples were fabricated using an EBM machine (Q20, Arcam, Gothenburg, Sweden) with the cylinder perpendicular to the building plate. The major process parameters are-accelerating voltage $60 \mathrm{KV}$, beam current $30 \mathrm{~mA}$, line spacing $0.22 \mathrm{~mm}$, scanning speed $24 \mathrm{~m} / \mathrm{s}$, layer thickness $0.09 \mathrm{~mm}$ and preheating temperature $700{ }^{\circ} \mathrm{C}$. The fabrication process was performed under a vacuum environment with a vacuum degree of below $8 \times 10^{-6} \mathrm{mbar}$. HIP treatment process was carried out at a temperature of $920^{\circ} \mathrm{C}$ for 2 hours with a pressure of $120 \mathrm{Mpa}$. 
Table 1. Chemical compositions of Ti6Al4V powder.

\begin{tabular}{ccccccccc}
\hline Element & Ti & Al & V & Fe & C & O & H & N \\
\hline Composition (wt. $\%)$ & Balance & 6.42 & 4.13 & 0.18 & 0.01 & 0.09 & 0.003 & 0.02 \\
\hline
\end{tabular}

\subsection{Characterization}

The surface morphology and surface roughness of as-built and HIPed samples were measured with a laser confocal microscope (Keygence, VK-250, Osaka, Japan). Then the samples for characterizing pores and voids were prepared and polished. The internal defects were observed using an optical microscope (Keygence, VHX-5000, Osaka, Japan). Relative density was measured using Archimedes method (MAY-Entirs120, Sartorious, Gottingen, Germany). After that, the polished sections were etched using a Kroll's agent ( $2 \mathrm{~mL} \mathrm{HF}, 4 \mathrm{~mL} \mathrm{HNO}_{3}$, and $94 \mathrm{~mL} \mathrm{H}_{2} \mathrm{O}$ ). Then the microstructures of both longitudinal (along the building direction) and transversal section (perpendicular to the building direction) were characterized using optical microscope (Keygence, VHX-5000, Osaka, Japan) and scanning electron microscopy (SEM) (FEI, Quanta 450FEG, Hillsboro, OH, USA). The internal defects especially dislocations were observed and phases were identified by selected-area electron diffraction (SAED) with a transmission electron microscopy (TEM) machine (FEI, Tecnai G2 F20, Hillsboro, OH, USA). Electron backscattered diffraction (EBSD) was conducted on well-polished transversal sections using a Nova NanoSEM 230 (FEI, Hillsboro, OH, USA) with a step size of $200 \mathrm{~nm}$. Tensile test specimens were cut from the cylindrical samples with wire cutting and then surface were polished after wire cutting. Mechanical properties including UTS, yield strength and elongation were measured along the building direction using an electronic universal material testing machine (Z050TEW, ZwickRoell, Berlin, Germany). The fracture surface was observed by SEM. Finally, the effect of HIP on the microstructures and mechanical properties of EBM-fabricated Ti6Al4V was discussed.

\section{Results}

The fabricated samples and its surface morphologies are shown in Figure 1. The surface roughness of as-built and HIPed samples was Ra $16.56 \mu \mathrm{m}$ and Ra $18.32 \mu \mathrm{m}$ respectively. These values indicated that EBM-fabricated Ti6Al4V parts typically had a relatively coarser surface and HIP had little effects on the surface roughness. Figure 2 shows the defects observed on well-polished transversal section of as-built and HIPed samples. It can be seen clearly that pores are the main defects for as-built samples (as shown in Figure 2a). After HIP, most of the pores were eliminated (as shown in Figure 2b) and nearly full dense samples were obtained. To measure the relative density, five specimens of both as-built and HIPed samples were prepared and each specimen was tested five time to calculate the average relative density and errors. Results showed that relative density increased from $(98.98 \pm 0.03) \%$ to $(99.73 \pm 0.04) \%$.
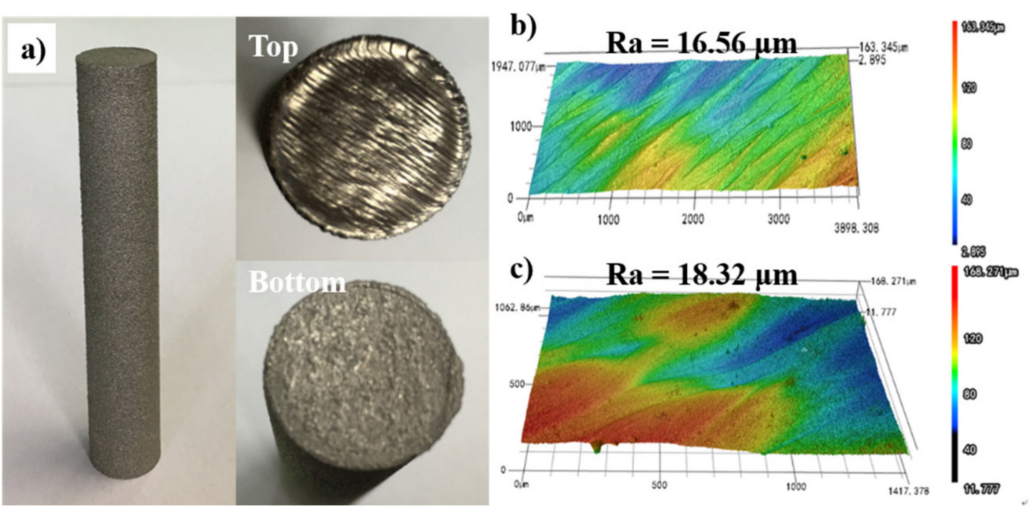

Figure 1. Cylindrical samples and surface morphology: (a) electron beam melting (EBM)-fabricated cylindrical samples; (b) surface morphologies of as-built sample; (c) surface morphologies of hot isostatic pressed (HIPed) sample. 

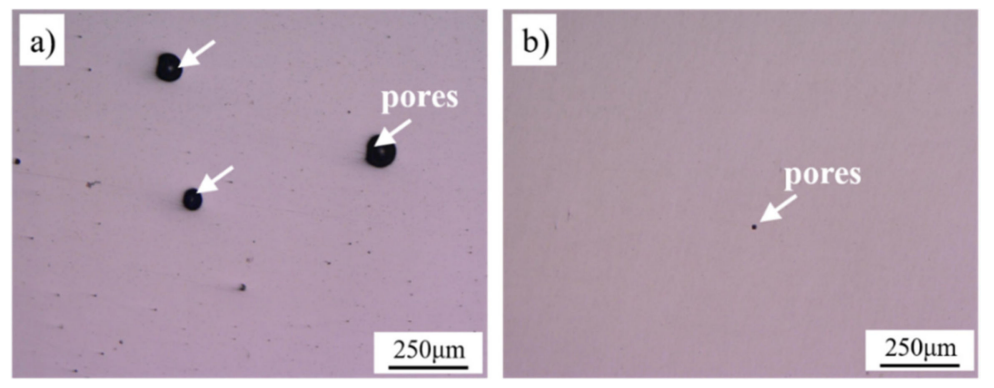

Figure 2. Defects observed on transversal section: (a) as-built sample; (b) HIPed sample.

The microstructures of longitudinal section along the building direction of as-build and HIPed samples are shown in Figure $3 a, b$. It can be seen that both samples had a typical columnar prior $\beta$ grain with continuous $\alpha$ phase at the grain boundary of prior $\beta$ and transformed $\alpha+\beta$ dual phase within the prior $\beta$ grain. Basketweave microstructures with acicular $\alpha$-lamellar were observed. The microstructures also demonstrated a preferred epitaxial growth along the building direction resulted from the maximum thermal gradient along this direction and the height of prior $\beta$ grain was 5-10 times of layer thickness. Comparing the longitudinal microstructures of the as-built and HIPed samples, it can be seen that HIP did not alter the fundamental features of its microstructures. However, from the transversal microstructures of the as-built and HIPed samples shown in Figure 3c,d, we can tell that the major microstructural differences between as-built and HIPed samples were the thickness of $\alpha$ lamellar and the proportion of $\alpha$ and $\beta$ phase. To compute the average $\alpha$ lamellar thickness, 10 measures of each sample were conducted. As we calculated, the average $\alpha$ lamellar thickness of as-built and HIPed samples was $0.71 \pm 0.15 \mu \mathrm{m}$ and $2.49 \pm 1.29 \mu \mathrm{m}$. As for the proportion of $\alpha$ and $\beta$ phase, it is quite difficult to calculate the precise values. Using an image processing method, the ratio of $\beta$ phase was roughly evaluated. The ratio of $\beta$ phase for as-built and HIPed sample was around $4.7 \%$ and $10.5 \%$ respectively. Therefore, the major effects of HIP on microstructures of EBM-fabricated Ti6Al4V include the increase of $\alpha$ lamellar thickness and $\beta$ phase ratio due to the heat treatment at high temperature.

Figure 4 shows the TEM characterization of as-built and HIPed samples. The comparison of TEM morphology between as-built and HIPed samples (shown in Figure 4b,e) indicated that the $\alpha$ lamellar thickness of HIPed samples was larger than that of as-built sample. This was in accordance with the results observed with SEM. The electron diffraction patterns of $\alpha$ phase and $\beta$ phase were obtained by selected area electron diffraction. It can be seen that $\beta$ phase existed between $\alpha$ lamellars and the thickness of $\beta$ phase was between ten of nanometers to hundreds of nanometers. The morphologies of dislocations between as-built and HIPed samples were also quite different. Bended dislocation networks were found in the as-built sample (shown in Figure 4a). While for the HIPed sample, much shorter dislocations with directions parallel to each other were observed (Figure $4 \mathrm{~d}$ ). The as-built sample also had a much larger dislocation density than HIPed sample that was resulted from the large cooling rate during the fabrication process. While for the HIPed sample, the cooling rate during the HIP process was much smaller, therefore, dislocation density was greatly reduced. 

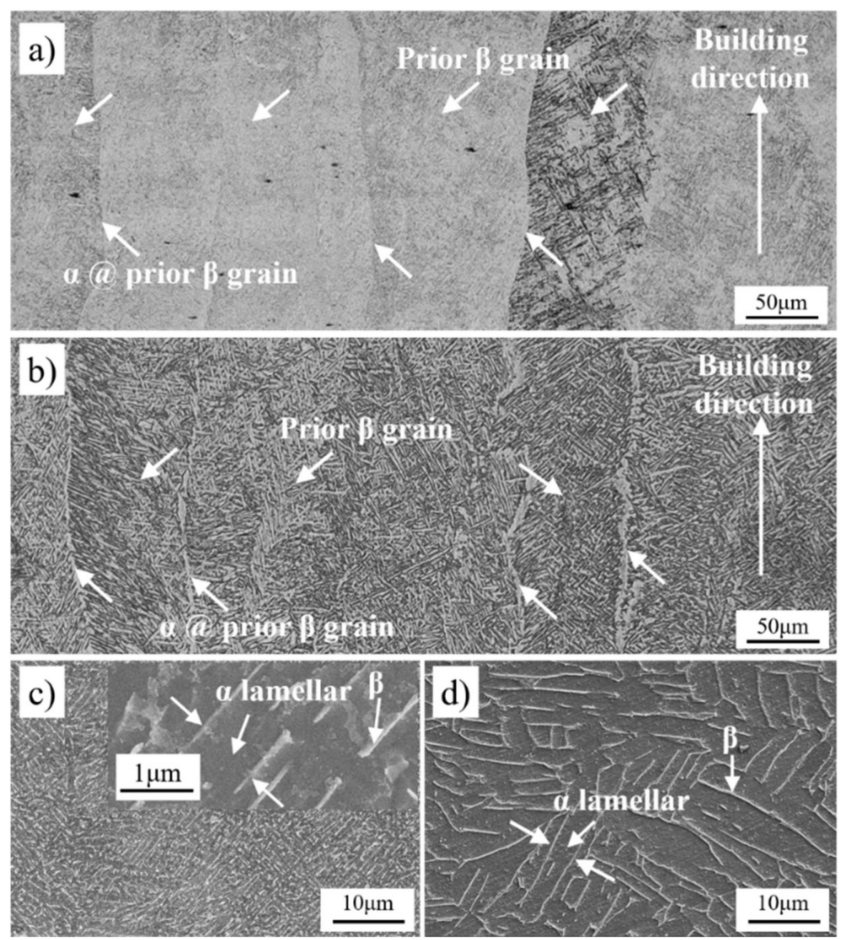

Figure 3. Microstructures of as-built and HIPed sample: (a) microstructures of longitudinal section of as-built sample; (b) microstructures of longitudinal section of HIPed sample; (c) microstructures of transversal section of as-built sample, the inset represent a magnified image; (d) microstructures of transversal section of HIPed sample.

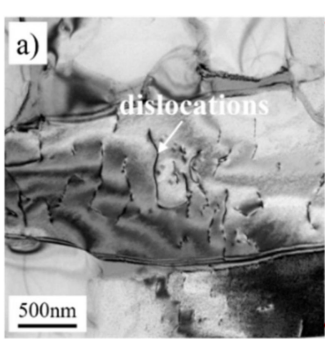

d)

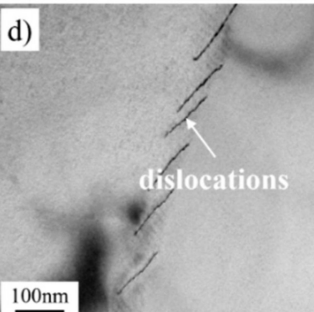

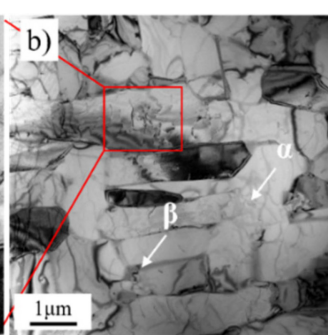

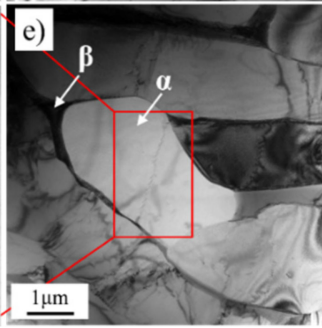

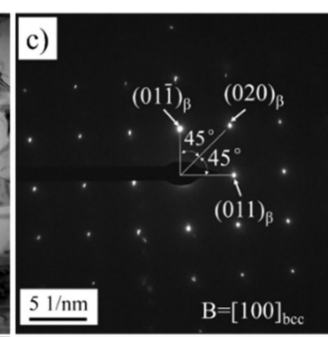

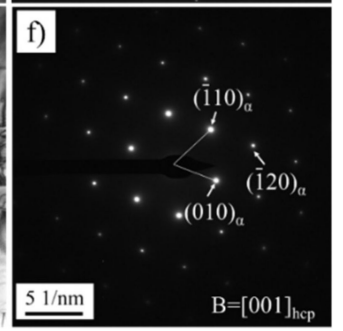

Figure 4. Transmission electron microscopy (TEM) characterization of as-built and HIPed samples, (a) dislocation of as-built sample, (b) TEM image of as-built sample, (c) electron diffraction pattern of $\beta$ phase, (d) dislocations of HIPed sample, (e) TEM image of HIPed sample, (f) electron diffraction pattern of $\alpha$ phase.

Figure 5 shows the EBSD analysis of as-built and HIPed samples. Figure 5a-f illustrates the grain orientation mapping, phase indexing and grain size distribution of the as-built and HIPed sample respectively. From these data, it can be seen that the $\beta$ phase fraction of HIPed samples was much larger than that of as-built sample. To be noted, the thickness of a certain portion of $\beta$ phase was less than $100 \mathrm{~nm}$. As a result, only part of the $\beta$ phase was able to be indexed due to limited step size of $200 \mathrm{~nm}$. Therefore, the fraction of $\beta$ phase for both samples could only be qualitatively evaluated. However, it is evident that the fraction of $\beta$ phase increased a lot after HIP and this was in accordance 
with the previous evaluation from the SEM metallography. The grain size distribution in terms of area fraction observed on the transversal section was calculated. The grain size values were exported to compute the average grain size and errors. The average grain size of as-built and HIPed samples was $7.96 \pm 1.21 \mu \mathrm{m}$ and $11.34 \pm 1.89 \mu \mathrm{m}$ respectively. Therefore, the grain size increased roughly $42.5 \%$ after HIP. The pole figures of $\alpha$ phase and $\beta$ phase are shown in Figure $5 \mathrm{~g}$, h. Apparently, both $\alpha$ phase and $\beta$ phase showed a certain degree of texture with $<0001>$ and $<001>$ that was parallel to the building direction and $\beta$ phase showed a stronger texture intensity. This texture might lead to the anisotropy of mechanical properties. It was also found that HIP did not alter the texture characteristics of microstructures.
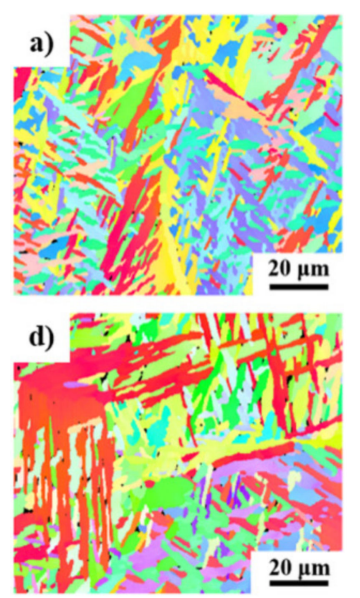

b)

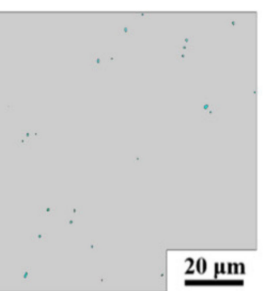

e)

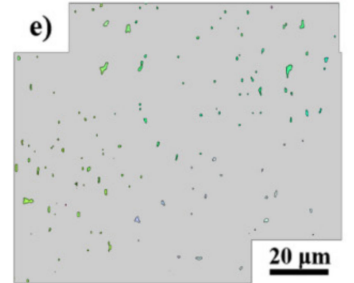

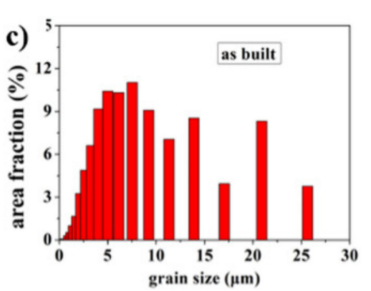

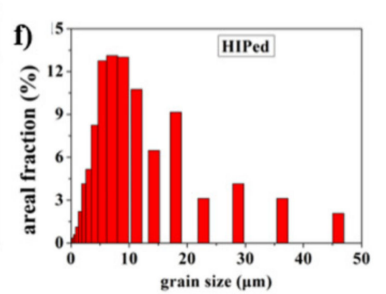

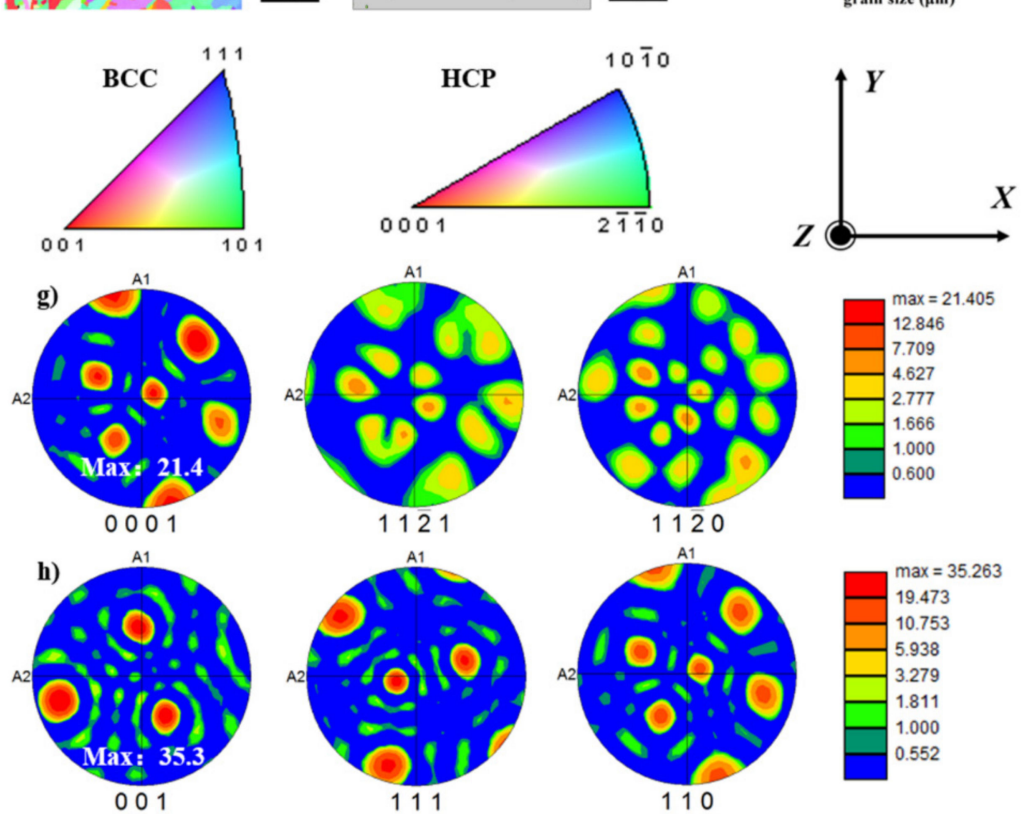

Figure 5. Electron backscattered diffraction (EBSD) analysis of as-built and HIPed samples: (a) grain orientation mapping of as-built sample on the transversal section; (b) phase indexing of as-built sample (black represents $\alpha$ phase); (c) grain size distribution of as-built sample; (d) IPF of HIPed sample; (e) phase indexing of HIPed sample; (f) grain size distribution of HIPed sample; (g) pole figure of $\alpha$ phase; (h) pole figure of $\beta$ phase.

Figure 6 shows the mechanical properties of the as-built and HIPed samples. Five tensile specimens were prepared for both as-built and HIPed samples. The average yield strength, UTS and elongation of the as-built samples was $(939.3 \pm 8.3) \mathrm{MPa},(986.9 \pm 4.4) \mathrm{MPa}$ and $(11.1 \pm 4.3) \%$ respectively. As for the HIPed sample, the values were $(887.9 \pm 3.1) \mathrm{MPa},(945.6 \pm 7.5) \mathrm{MPa}$ and $(18.8 \pm 4.6) \%$ respectively. It can be seen that yield strength and UTS slightly decreased and elongation greatly increased after HIP. 


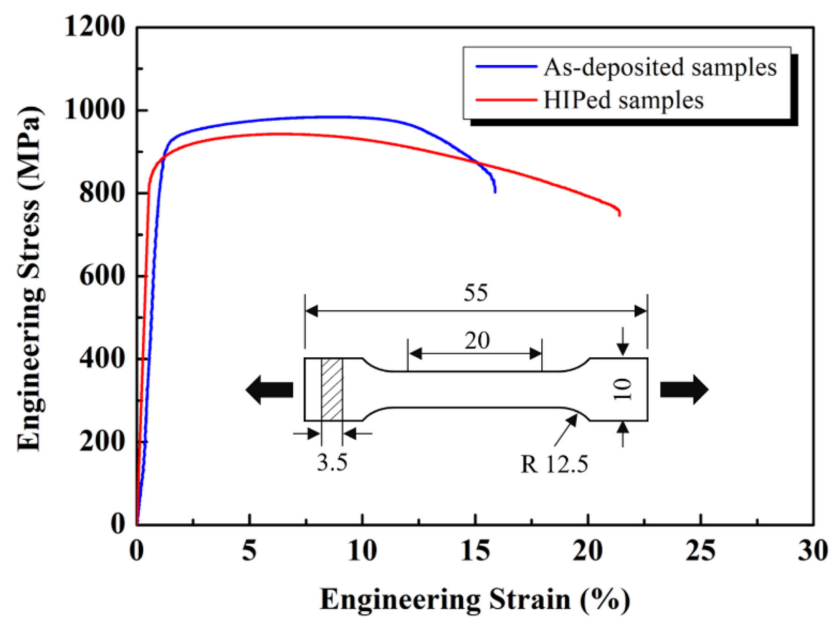

Figure 6. Tensile mechanical properties of as-built and HIPed samples.

Figure 7 shows the SEM characterization of the tensile fracture surface of the as-built and HIPed sample. It can be seen that both samples demonstrated a ductile fracture surface featured with clear necking and dimples on the fracture surface. However, the necking of the HIPed sample was more evident than the as-built sample and the dimple depth and size was also larger. This clearly showed that HIPed samples had larger ductility than the as-built sample.
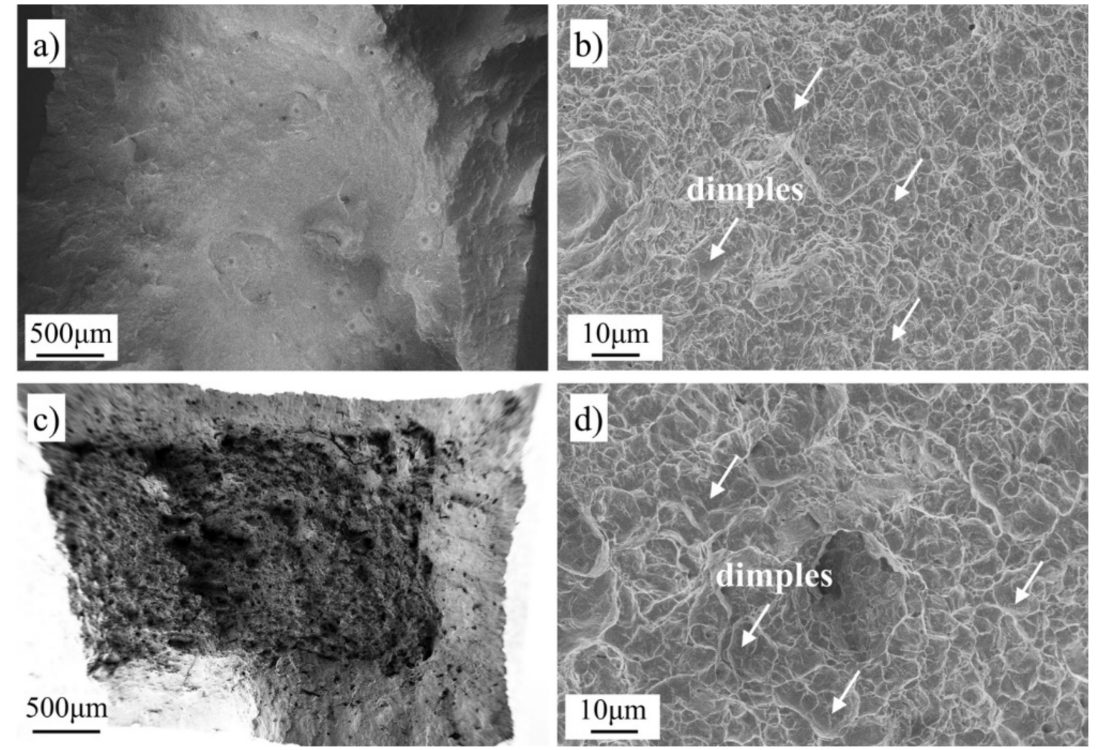

Figure 7. Scanning electron microscopy (SEM) characterization of the tensile fracture surface, (a) and (b) tensile fracture surface of the as-built sample, (c) and (d) tensile fracture surface of the HIPed sample.

\section{Discussion}

The above section describes the surface morphologies, internal defects, microstructures, grain orientation, phase distribution, grain size distribution, texture strength, dislocation, mechanical properties and tensile fracture surface analysis of the as-built and HIPed EBM-fabricated Ti6Al4V samples. By comparing the differences between the two types of samples, the effects of HIP on EBM-fabricated Ti6Al4V include-(1) HIP had little influence on its surface morphologies; (2) HIP greatly reduced the internal defects especially pores and voids and thereby increased the relative density from $(98.98 \pm 0.03) \%$ to $(99.73 \pm 0.04) \%$; (3) HIP did not alter the fundamental features of microstructures. Epitaxillay grown columnar $\beta$ grain with continuous $\alpha$ at the prior $\beta$ grain boundary and $\alpha+\beta$ dual phase within prior $\beta$ grain was maintained after HIP process; (4) HIP increased the $\alpha$ lamellar thickness from $0.71 \pm 0.15 \mu \mathrm{m}$ to $2.49 \pm 1.29 \mu \mathrm{m}$, the average grain size from $7.96 \pm 1.21 \mu \mathrm{m}$ to 
$11.34 \pm 1.89 \mu \mathrm{m}$ in terms of area fraction on the transversal section and $\beta$ phase ratio from $4.7 \%$ to $10.5 \%$ due to the high temperature process; (5) HIP process did not alter the texture characteristics of the as-built Ti6Al4V and a certain degree of texture strength of both $\alpha$ phase and $\beta$ phase was observed for as-built and HIPed samples; (6) HIP altered the dislocation morphologies and reduced the dislocation length and density.

The above effects of HIP on EBM-fabricated Ti6Al4V finally led to the changes of mechanical properties, including - (1) the yield strength reduced from (939.3 \pm 8.3) MPa to (887.9 \pm 3.1$) \mathrm{MPa}$; (2) the ultimate strength reduced from $(986.9 \pm 4.4) \mathrm{MPa}$ to $(945.6 \pm 7.5) \mathrm{MPa}$; (3) the elongation increased from $(11.1 \pm 4.3) \%$ to $(18.8 \pm 4.6) \%$. Although slight reduction of both yield strength and ultimate strength was observed, the increase of ductility can ultimately lead to better overall mechanical performance. These values are similar to the values reported in references. For example, Persenot et al., reported $50 \mathrm{MPa}$ decrease of yield strength and 44\% increase of elongation after HIP [29]. Lu et al., found that the $\alpha$ lamellar thickness grew from less than $1 \mu \mathrm{m}$ to roughly $5 \mu \mathrm{m}$ and the $\beta$ phase ratio increased from $4.8 \%$ to $9.5 \%$ after HIP. The yield strength and ultimate strength decreased from $~ 920 \mathrm{MPa}$ to $\sim 810 \mathrm{MPa}$ and $\sim 1000 \mathrm{MPa}$ to $\sim 910 \mathrm{MPa}$ along with the elongation increased from $\sim 13 \%$ to $\sim 17.7 \%$ [24]. In our study, the yield strength, ultimate strength and elongation is slightly higher than reported values possibly due to the difference of shapes and geometries of test specimens.

Author Contributions: Conceptualization, C.L. (Changshi Lao) and Z.C.; writing, C.L. (Changyong Liu); Methodology, Z.M. and D.Y.; analysis, Y.D., M.J. and P.W. All authors have read and agreed to the published version of the manuscript.

Funding: This research was funded by Shenzhen Bureau of Industry and Information Technology, grant number ZDYBH201900000009 and ZDYBH201900000008; National Taipei University of Technology-Shenzhen University Joint Research Program, grant number 2020010.

Acknowledgments: The authors would like to acknowledge Jun Shen for providing the samples and valuable discussion on the results.

Conflicts of Interest: The authors declare no conflict of interest.

\section{References}

1. Dutta, B.; Froes, F.H. Additive manufacturing of titanium alloys. Adv. Mater. Process. 2014, 172, 18-23.

2. Qian, M.; Bourell, D.L. Additive manufacturing of titanium alloys. JOM 2017, 69, 2677-2678. [CrossRef]

3. Attar, H.; Ehtemam-Haghighi, S.; Kent, D.; Dargusch, M.S. Recent developments and opportunities in additive manufacturing of titanium-based matrix composites: A review. Int. J. Mach. Tool Manuf. 2018, 133, 85-102. [CrossRef]

4. Cansizoglu, O.; Harrysson, O.; Cormier, D.; West, H.; Mahale, T. Properties of ti-6al-4v non-stochastic lattice structures fabricated via electron beam melting. Mat. Sci. Eng. A Struct. 2008, 492, 468-474. [CrossRef]

5. Zhang, L.C.; Liu, Y.J.; Li, S.J.; Hao, Y.L. Additive manufacturing of titanium alloys by electron beam melting: A review. Adv. Eng. Mater. 2018, 20, 1700842. [CrossRef]

6. Facchini, L.; Magalini, E.; Robotti, P.; Molinari, A. Microstructure and mechanical properties of ti-6al-4v produced by electron beam melting of pre-alloyed powders. Rapid Prototyp. J. 2009, 15, 171-178. [CrossRef]

7. Murr, L.E.; Esquivel, E.V.; Quinones, S.A.; Gaytan, S.M.; Lopez, M.I.; Martinez, E.Y.; Medina, F.; Hernandez, D.H.; Martinez, E.; Martinez, J.L.; et al. Microstructures and mechanical properties of electron beam-rapid manufactured ti-6al-4v biomedical prototypes compared to wrought ti-6al-4v. Mater. Charact. 2009, 60, 96-105. [CrossRef]

8. Al-Bermani, S.S.; Blackmore, M.L.; Zhang, W.; Todd, I. The origin of microstructural diversity, texture, and mechanical properties in electron beam melted ti-6al-4v. Metall. Mater. Trans. A 2010, 41A, 3422-3434. [CrossRef]

9. Safdar, A.; Wei, L.Y.; Snis, A.; Lai, Z. Evaluation of microstructural development in electron beam melted ti-6al-4v. Mater. Charact. 2012, 65, 8-15. [CrossRef]

10. Gong, X.B.; Lydon, J.; Cooper, K.; Chou, K. Characterization of ti-6al-4v powder in electron beam melting additive manufacturing. Int. J. Powder Metall. 2015, 51, 25-34. 
11. Tang, H.P.; Qian, M.; Liu, N.; Zhang, X.Z.; Yang, G.Y.; Wang, J. Effect of powder reuse times on additive manufacturing of ti-6al-4v by selective electron beam melting. JOM 2015, 67, 555-563. [CrossRef]

12. Nandwana, P.; Kirka, M.M.; Paquit, V.C.; Yoder, S.; Dehoff, R.R. Correlations between powder feedstock quality, in situ porosity detection, and fatigue behavior of ti-6al-4v fabricated by powder bed electron beam melting: A step towards qualification. JOM 2018, 70, 1686-1691. [CrossRef]

13. Guo, C.; Ge, W.; Lin, F. Effects of scanning parameters on material deposition during electron beam selective melting of ti-6al-4v powder. J. Mater. Process. Technol. 2015, 217, 148-157. [CrossRef]

14. Abdeen, D.H.; Palmer, B.R. Effect of processing parameters of electron beam melting machine on properties of ti-6al-4v parts. Rapid Prototyp. J. 2016, 22, 609-620. [CrossRef]

15. Cunningham, R.; Narra, S.P.; Ozturk, T.; Beuth, J.; Rollett, A.D. Evaluating the effect of processing parameters on porosity in electron beam melted ti-6al-4v via synchrotron X-ray microtomography. JOM 2016, 68, 765-771. [CrossRef]

16. Pushilina, N.; Syrtanov, M.; Kashkarov, E.; Murashkina, T.; Kudiiarov, V.; Laptev, R.; Lider, A.; Koptyug, A. Influence of manufacturing parameters on microstructure and hydrogen sorption behavior of electron beam melted titanium ti-6al-4v alloy. Materials 2018, 11, 763. [CrossRef]

17. Maizza, G.; Caporale, A.; Polley, C.; Seitz, H. Micro-macro relationship between microstructure, porosity, mechanical properties, and build mode parameters of a selective-electron-beam-melted ti-6al-4v alloy. Metals Basel 2019, 9, 786. [CrossRef]

18. Prisco, U.; Astarita, A.; El Hassanin, A.; Franchitti, S. Influence of processing parameters on microstructure and roughness of electron beam melted ti-6al-4v titanium alloy. Mater. Manuf. Process. 2019, 34, 1753-1760. [CrossRef]

19. Antonysamy, A.A.; Prangnell, P.B.; Meyer, J. Influence of build geometry on beta grain structure and texture during additive layer manufacture (alm) of ti-6al-4v by electron beam selective melting. In Proceedings of the Ti-2011: 12th World Conference on Titanium, Beijing, China, 19-24 June 2011; Volume 3, pp. 1830-1834.

20. Antonysamy, A.A.; Meyer, J.; Prangnell, P.B. Effect of build geometry on the $\beta$-grain structure and texture in additive manufacture of ti6al4v by selective electron beam melting. Mater. Charact. 2013, 84, 153-168. [CrossRef]

21. Kok, Y.H.; Tan, X.P.; Loh, N.H.; Tor, S.B.; Chua, C.K. Geometry dependence of microstructure and microhardness for selective electron beam-melted ti-6al-4v parts. Virtual Phys. Prototy. 2016, 11, 183-191. [CrossRef]

22. Hrabe, N.; Gnaupel-Herold, T.; Quinn, T. Fatigue properties of a titanium alloy (ti-6al-4v) fabricated via electron beam melting (ebm): Effects of internal defects and residual stress. Int. J. Fatigue 2017, 94, 202-210. [CrossRef]

23. Chern, A.H.; Nandwana, P.; Yuan, T.; Kirka, M.M.; Dehoff, R.R.; Liaw, P.K.; Duty, C.E. A review on the fatigue behavior of ti-6al-4v fabricated by electron beam melting additive manufacturing. Int. J. Fatigue 2019, 119, 173-184. [CrossRef]

24. Lu, S.L.; Tang, H.P.; Ning, Y.P.; Liu, N.; Stjohn, D.H.; Qian, M. Microstructure and mechanical properties of long ti-6al-4v rods additively manufactured by selective electron beam melting out of a deep powder bed and the effect of subsequent hot isostatic pressing. Metall. Mater. Trans. A 2015, 46A, 3824-3834. [CrossRef]

25. Lu, S.L.; Tang, H.P.; Nai, S.M.L.; Sun, Y.Y.; Wang, P.; Wei, J.; Qian, M. Intensified texture in selective electron beam melted ti-6al-4v thin plates by hot isostatic pressing and its fundamental influence on tensile fracture and properties. Mater. Charact. 2019, 152, 162-168. [CrossRef]

26. Tammas-Williams, S.; Withers, P.J.; Todd, I.; Prangnell, P.B. The effectiveness of hot isostatic pressing for closing porosity in titanium parts manufactured by selective electron beam melting. Metall. Mater. Trans. A 2016, 47A, 1939-1946. [CrossRef]

27. Wang, J.; Tang, H.P.; Yang, K.; Liu, N.; Jia, L.; Qian, M. Selective electron beam manufacturing of ti-6al-4v strips: Effect of build orientation, columnar grain orientation, and hot isostatic pressing on tensile properties. JOM 2018, 70, 638-643. [CrossRef]

28. Hernandez-Nava, E.; Mahoney, P.; Smith, C.J.; Donoghue, J.; Todd, I.; Tammas-Williams, S. Additive manufacturing titanium components with isotropic or graded properties by hybrid electron beam melting/hot isostatic pressing powder processing. Sci. Rep. 2019, 9, 4070. [CrossRef] 
29. Persenot, T.; Martin, G.; Dendievel, R.; Buffiere, J.Y.; Maire, E. Enhancing the tensile properties of ebm as-built thin parts: Effect of hip and chemical etching. Mater. Charact. 2018, 143, 82-93. [CrossRef]

30. Khrapov, D.; Koptyug, A.; Manabaev, K.; Leonard, F.; Mishurova, T.; Bruno, G.; Cheneler, D.; Loza, K.; Epple, M.; Surmenev, R.; et al. The impact of post manufacturing treatment of functionally graded ti6al4v scaffolds on their surface morphology and mechanical strength. J. Mater. Res. Technol. 2020, 9, 1866-1881. [CrossRef] 